\title{
Procedural sedation with dexmedetomidine for ultrasound guided central venous cannulation in agitated, high risk critically ill patients. A series of three cases
}

\author{
Gentle S Shrestha ${ }^{1}$, Bashu Dev Parajuli², Amit Sharma Bhattarai ${ }^{3}$
}

\begin{abstract}
Central venous cannulation is a commonly performed procedure in ICU. Even in the experienced hands, it is not free of complications. Acute mechanical adverse events are more likely in agitated and uncooperative patients. Ultrasound guided cannunation of internal jugular vein is associated with higher success rate and fewer mechanical complications when compared with traditional techniques. Dexmedetomidine has been used as a safe and effective agent for procedural sedation in a wide variety of patients. Here we successfully used dexmedetomidine for ultrasound guided central venous cannulation of internal jugular vein in uncooperative high risk patients, even at the extremes of age.
\end{abstract}

Key-words: dexmedetomidine, ultrasound guided central venous cannulation, high risk patient.

\section{Introduction:}

Central venous catheterization is frequently indicated in critically ill patients. They allow delivery of medications, intravenous fluids, parenteral nutrition and monitoring of hemodynamic variables. ${ }^{1}$ Mechanical complications like failure to place catheter, pneumothorax, arterial puncture, air embolism, etc are not uncommon and has been demonstrated in 5 to $29 \%$ of catheterization attempts. ${ }^{2}$ It is more common in agitated and uncooperative patients. There is compelling evidence that ultrasound-guided central venous catheter (CVC) insertion through the internal jugular veins is associated with higher success rate and fewer mechanical complications compared with traditional techniques based on external anatomical landmarks. ${ }^{3}$ There are strong recommendations for routine use of ultrasound guidance for central venous access in both adults and children. ${ }^{4}$

Dexmedetomidine is a highly selective $\alpha-2$ adrenoceptor agonist with sedative, sympatholytic, analgesic and anxiolytic

1. Gentle S Shrestha, Lecturer, Department of Anaesthesiology, Tribhuvan Unviersity Teaching Hospital, Maharajgunj, Kathmandu, Nepal

2. Bashu Dev Parajuli, Lecturer, Department of Anaesthesiology, Tribhuvan Unviersity Teaching Hospital, Maharajgunj, Kathmandu, Nepal

3. Amit Sharma Bhattarai, Lecturer, Department of Anaesthesiology, Tribhuvan Unviersity Teaching Hospital, Maharajgunj, Kathmandu, Nepal

Corresponding Author:

Dr. Gentle S Shrestha

MBBS, MD, FACC, EDIC, MRCP(I), FCCP

Intensivist \& Anaesthesiologist

Tribhuvan University Teaching Hospital

Maharajgunj, Kathmandu, Nepal

Email: gentlesunder@hotmail.com

Phone: +77-9841248584 property but without significant respiratory depressant effects. It has been effectively used for procedural sedation both in adults and children.5,6 Common adverse effects associated with use of dexmedetomidine are hypotension and bradycardia. The risk of bradycardia being significantly higher when both a loading dose and high maintenance dose $(>0.7 \mu \mathrm{g} / \mathrm{kg} / \mathrm{hr})$ was used. ${ }^{6}$ Use of dexmedetomidine at the usual recommended dose may be associated with increased incidence of hypotension in older adults. ${ }^{7}$

Here we successfully performed ultrasound guided CVC insertion through internal jugular approach with dexmedetomidine for procedural sedation in three uncooperative high risk critically ill patients.

\section{Case History:}

Case 1

A 54 years old male, a case of traumatic brain injury, presented with the Glasgow Coma Scale of 12 (E3M5V4). Patient was very agitated and delirious with Richmond Agitation Sedation Scale (RASS) of +3 . Initially, landmark guided central venous cannulation was attempted under procedural sedation with intravenous Haloperidol $10 \mathrm{mg}$, which failed with two events of arterial puncture. Patient was loaded with Dexmedetomidine $1 \mu \mathrm{g} / \mathrm{kg}$ over 15 minutes and then put on $0.5 \mu \mathrm{g} / \mathrm{kg} / \mathrm{hr}$. His RASS decreased to -1 . Right internal jugular vein was successfully cannulated under real time ultrasonographic guidance in single attempt, without any complications. His peri-procedural haemodynamics, respiration and oxygen saturation remained stable.

Case 2

An eight months old child, a case of tuberous sclerosis, was on regular anti-convulsants and steroids for epilepsy. He was admitted with severe pneumonia. He was planned for central venous cannulation due to difficult intravenous access. He weighed $15 \mathrm{~kg}$ and had anticipated difficult airway. He was tachypnoic (respiratory rate of $45 / \mathrm{min}$ ) with heart rate of $150 /$ min and maintaining oxygen saturation of $91 \%$ with 
oxygen supplementation via facemask at 8 litres/min. Child was agitated and restless. Through a peripheral intravenous access, dexmedetomidine $1 \mu \mathrm{g} / \mathrm{kg}$ was administered over 15 minutes. Child became calm with respiratory rate of $35 / \mathrm{min}$, heart rate of $140 / \mathrm{min}$ and maintaining $\mathrm{SPO}_{2}$ of $90 \%$ on supplemental oxygen. He was then put on maintenance infusion at $0.4 \mu \mathrm{g} / \mathrm{kg} / \mathrm{hr}$. Right internal jugular vein was successfully cannulated under real time ultrasonographic guidance in first attempt. Procedure was uneventful.

\section{Case 3}

A 91 years old lady was admitted to ICU with diagnosis of acute severe pancreatitis with health-care associated pneumonia and atrial fibrillation with fast ventricular rate. She was agitated and delirious with RASS of +3 . Her heart rate was 155/minute; blood pressure was 120/70 mm Hg; respiratory rate of $24 /$ minute and maintaining oxygen saturation of $90 \%$ with supplemental $60 \%$ oxygen. She remained agitated after administering Haloperidol $5 \mathrm{mg}$ intravenously. She was administered dexmedetomidine $0.5 \mu$ $\mathrm{g} / \mathrm{kg}$ over 15 mins followed by maintenance infusion of $0.2 \mu$ $\mathrm{g} / \mathrm{kg} / \mathrm{hr}$. Her RASS decreased to -1 . Successful central venous cannulation was done through right internal jugular approach under real time ultrasonographic guidance in a single attempt. Her post-procedure heart rate was 150/minute; blood pressure of $100 / 60 \mathrm{~mm} \mathrm{Hg}$; respiratory rate of $20 /$ minute and maintaining $\mathrm{SPO}_{2}$ of $90 \%$.

\section{Discussion:}

Mechanical complications during central venous cannulation of critically ill patients are not uncommon even when performed by experienced operator when landmark guided technique is used. Complications are higher after two unsuccessful cannulation attempts. ${ }^{8}$ Compared with landmark method, real time ultrasound guidance for cannulation of internal jugular veins is associated with higher success rate, fewer mechanical complications and shorter time for cannulation both in adults and infants. ${ }^{3,9}$ So, real time ultrasound guidance was used in all three cases. In the first case, ultrasound guidance was used since the landmark guided technique failed. In all three patients, right internal jugular vein was successfully cannulated in first attempt without any mechanical complications.

Dexmedetomidine have been used to provide sedation in diverse ICU populations, both in adults and children. ${ }^{5,6}$ It has also been safely used in patients with known cardiac disease. ${ }^{10}$ It is devoid of significant respiratory depressant effect, but is associated with bradycardia when used at higher dose (maintenance dose of more than $0.7 \mu \mathrm{g} / \mathrm{kg} / \mathrm{hr}$ ). ${ }^{6}$ Elderly patients are more susceptible to hypotension. ${ }^{7}$ Appropriate dosing in elderly patients is not well studied.

We used dexmedetomidine at low and recommended dose in first and second case (loading dose of $1 \mu \mathrm{g} / \mathrm{kg}$ followed by continuous infusion of 0.4 to $0.5 \mu \mathrm{g} / \mathrm{kg} / \mathrm{hr}$ ). For the elderly patient (third case), we used half of the usual dose. In all the cases, dexmedetomidine infusion significantly decreased agitation, yielding a calm, yet haemodynamically stable patients for CVC insertion. It was well tolerated in third case with atrial fibrillation.

To conclude, procedural sedation with dexmedetomidine, coupled with real time ultrasonographic guidance can be valuable for safe central venous cannulation in agitated and uncooperative high risk critical ill patients in a wide range of age and clinical conditions. Larger well structured trials will be valuable to justify the safety, feasibility and efficacy of the therapeutic combination.

\section{References:}

1. Eisen LA, Narasimhan M, Berger JS, Mayo PH, Rosen MJ, Schneider RF. Mechanical complications of central venous catheters. J Intensive Care Med 2006;21:40-6.

2. McGee DC, Gould MK. Preventing complications of central venous catheterization. $N$ Engl $J$ Med 2003;348:1123-33.

3. Frykholm P, Pikwer A, Hammarskjold F, Larsson AT, Lidgren S, Lidwall R, et al. Clinical guidelines on central venous catheterisation. Swedish Society of Anaesthesiology and Intensive Care Medicine. Acta Anaesthesiol Scand 2014;58:508-24.

4. Lamperti M, Bodenham AR, Pittiruti M, Blaivas M, Augoustides JG, Elbarbary $\mathrm{M}$, et al. International evidence-based recommendations on ultrasound-guided vascular access. Intensive Care Med 2012;38:1105-17.

5. Carroll CL, Krieger D, Campbell M, Fisher DG, Comeau LL, Zucker AR. Use of dexmedetomidine for sedation of children hospitalized in the intensive care unit. $J$ Hosp Med 2008;3:142-7.

6. Tan JA, Ho KM. Use of dexmedetomidine as a sedative and analgesic agent in critically ill adult patients: a meta-analysis. Intensive Care Med 2010;36:926-39.

7. Gratz I, Jean S, Deal E, Pukenas E, Allen E, Torjman MC. Dexmedetomidine causes increased hypotension in older adults when used for cataract surgery compared with propofol. Open Journal of Anesthesiology 2013;3:237-42.

8. Schummer W, Schummer C, Rose N, Niesen WD, Sakka SG. Mechanical complications and malpositions of central venous cannulations by experienced operators. A prospective study of 1794 catheterizations in critically ill patients. Intensive Care Med 2007;33:1055-9.

9. Hind D, Calvert N, McWilliams R, Davidson A, Paisley $\mathrm{S}$, Beverly C, et al. Ultrasonic locating devices for central venous cannulation: meta-analysis. BMJ 2003;327:361

10. Ji F, Li Z, Nguyen H, Young N, Shi P, Fleming N, et al. Perioperative dexmedetomidine improves outcomes of cardiac surgery. Circulation 2013;127:1576-84. 